\title{
MEASUREMENT OF DYNAMIC SORPTION BEHAVIOUR OF SMALL SPECIMENS OF PINUS RADIATA - INFLUENCE OF WOOD TYPE AND MOISTURE CONTENT ON DIFFUSION RATE*
}

\author{
R. Sargent ${ }^{1}$, S. Riley ${ }^{2}$, L. Schöttle ${ }^{3}$
}

\begin{abstract}
Sorption behaviour of radiata pine has been investigated by weighing small specimens continuously during isothermal step changes in relative humidity. The use of wood specimens shorter in the longitudinal direction than the average tracheid length of radiata pine ensures that all tracheids in a specimen are exposed, reducing the effect of wood structure on bound water transport. The small size also allows the specimens to be prepared from a single band of earlywood or latewood.

Using the dynamic sorption platform developed at Scion, a number of sorption experiments were undertaken comparing dynamic sorption behaviour of individual bands of earlywood and latewood, which had been heat treated to mimic the chemical changes that occur during high temperature drying.

Diffusion coefficients and surface emission coefficients have been calculated from the sorption data, and are presented here. Earlywood and latewood had different sorption behaviour, but no measurable changes in sorption behaviour were seen with the different heat treatments. Diffusion coefficients were strongly dependent on moisture content.

Keywords: Drying, Temperature, Small Samples, Surface Emission Coefficient.
\end{abstract}

\section{INTRODUCTION}

The sorption behaviour of water in wood influences the behaviour of wood at all stages of processing and use - drying, storage, manufacturing and service. Understanding this sorption behaviour is critical to optimising the drying process, and ensuring consistent, quality wood products.

If there are differences in sorption behaviour of earlywood and latewood, these could cause boards with different growth ring orientations, or with differing amounts of earlywood and latewood on the surfaces to dry at different rates, and behave differently in service. The measurement of sorption in very small specimens would allow for specimens to consist entirely of earlywood or latewood from a single growth ring. Due to the anisotropic and heterogeneous nature of wood, the use of small wood specimens makes it easier to ensure that the wood in each specimen is uniform, and has a similar composition to other specimens used, especially in species with very large growth rings, such as radiata pine. The use of small specimens also has the advantage of allowing the longitudinal direction of the specimen to be made shorter than the length of an individual wood fibre ( $\sim 5 \mathrm{~mm}$ in radiata pine). This means that the internal surfaces of all the cell walls in the specimen are open to the atmosphere, which simplifies the diffusion dynamics of bound water, by reducing the effects of wood structure. This is particularly useful when comparing earlywood and latewood, since the cell wall thickness, and wood basic density are so different between the wood types (Kininmonth and Whitehouse 1991). Separating out the diffusion behaviour of the cell walls from the overall wood structure serves as a starting point to understanding the interaction of diffusion in the cell wall, and diffusion through the wood structure for earlywood and latewood.

\footnotetext{
This paper was originally presented at the 11 Iufro Wood Drying Conference, Skelleftea-Sweden, January 2010, and has been updated. 1Biopolymer and Green Chemical Technologies, Scion. 49 Sala Street, Rotorua, New Zealand

2Wood and Biofibre Technologies, Scion. 49 Sala Street, Rotorua, New Zealand.

3University of Applied Sciences, Rosenheim, Germany.

Corresponding author: rosie.sargent@scionresearch.com

Received: 23.03.2010. Accepted: 29.06. 2010
} 
Riley et al. (2008) developed the dynamic sorption platform, which weighs wood samples (of around $0.1 \mathrm{gram}$ ) continuously while altering the ambient humidity at a constant temperature. Previous analysis of sorption data at Scion looked at the change in moisture content of the specimens using a generalised mathematical description of the curve shape, rather than linking the sorption dynamics to physical wood properties (Riley et al.2008). This was useful for directly comparing the behaviour of a series of wood specimens, but had limited use for predicting wood behaviour. A data analysis method was needed that could relate the measured dynamic weight change of a specimen to the diffusion behaviour from the tracheid surface into the cell wall.

Mass transfer of water from moist air onto a small wood specimen has two major components - the diffusion from the moist air onto the wood surface, and diffusion of water within the wood cell walls. These two components can either be determined separately (Cai and Avramidis 1997, Chen et al. 1995, Liu 1989, Shi 2007, Wadsö 1993), or grouped into a single diffusion term (Wadsö 1994, Cai 2005). Both approaches have been used to analyse dynamic sorption behaviour in wood, and a variety of analysis methods have been used for each approach.

The solution to Fick's law for the sorption response to a step change in concentration (Crank 1975) can be used to give an expected change in moisture content of a specimen over time following a step change in humidity. Due to the previous success in comparing the moisture content curves from the Scion sorption platform with a calculated ideal response curve (Riley et al. 2008); fitting Crank's equation to data from the dynamic sorption platform was an obvious starting point for sorption analysis.

There are a large number of studies separating the internal diffusion from the effects of the wood surface for dynamic sorption in wood. Wadsö (1993) used wood specimens of different thicknesses and measured their mass change in response to a step change in humidity. By comparing the 'half sorption time' (the time at which half the total sorption has taken place) for each specimen, the diffusion coefficient and surface emission coefficient were determined. This method could not be used in the current study, because the cell wall is taken to be the specimen thickness, so altering the specimen thickness is not possible. Liu (1989) and Liu and Simpson (1996) used Newman's solution to Fick's second law to evaluate the diffusion coefficient and the surface emission coefficient at the time to half sorption. Cai and Avramidis (1997) used Newman's solution and a simplex search method to find optimal values of the diffusion coefficient and surface emission coefficient to fit curves to experimental data. Similar methods have also been employed, but with different optimisation techniques (Chen et al. 1995, Shi 2007).

Stamm (1959) measured the diffusion rate of bound water in wood cell walls by filling the void spaces in wood specimens with a low melting point metal alloy to eliminate vapour and capillary moisture movement through the wood. He found that the diffusion rate increased exponentially with increasing wood moisture content.

\section{MATERIALS AND METHODS}

Detailed information on the operation of the Dynamic Sorption Platform has been published previously (Riley et al. 2008).

A single flitch of air dried radiata pine from the central North Island of New Zealand was used in this study. A biscuit of $5 \mathrm{~mm}$ in the longitudinal direction was cut from the pith to the outside of the tree. From this biscuit, small wood specimens were cut, comprising entirely of either earlywood and latewood, from both heartwood and sapwood - giving four wood types; Sapwood Earlywood (S E), Sapwood Latewood (S L), Heartwood Earlywood (H E), Heartwood Latewood (H L). The 5 mm biscuit was first cut into individual bands of earlywood and latewood with a bandsaw. The width of these bands was $5 \mathrm{~mm}$ or less in the radial direction. The bands were then cut in the tangential direction 
to give a wood specimen weighing around 0.07 grams. Earlywood specimens tended to be roughly cubic, but latewood specimens were quite elongated in the tangential direction. Two specimens of each wood type were then heat treated in an oven, to mimic the chemical changes wood undergoes during high temperature drying. The heat treatments used were; $150^{\circ} \mathrm{C}$ for 4 hours, $150^{\circ} \mathrm{C}$ for 2 hours, $90^{\circ} \mathrm{C}$ for 4 hours, and the control specimens which were not heat treated.

The specimens were painted with acrylic paint on the radial and tangential faces to prevent mass transfer through the sides of the specimen. (Figure 1). After the experiments were completed it was discovered that acrylic paint has a similar diffusion coefficient to radiata pine (van der Zanden and Goossens 2003). Although this will have affected the sorption experiments, the similarity in diffusion coefficients may reduce the effect.

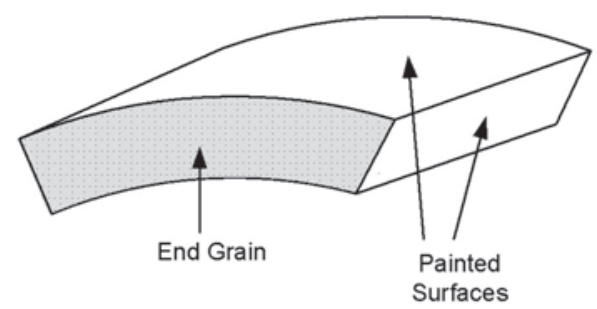

Figure 1. Thin latewood specimen, showing painted surfaces (white) and unpainted end grain (grey).

The prepared specimens had a threaded hole drilled and tapped into them, so they could be fixed to the dynamic sorption platform (Figure 2). Some latewood specimens needed to be attached with a weighed brass nut, as they were too thin to screw onto the mounting points firmly by themselves. The set of 30 specimens remained on the sorption platform for the duration of the sorption experiments (Figure 3)

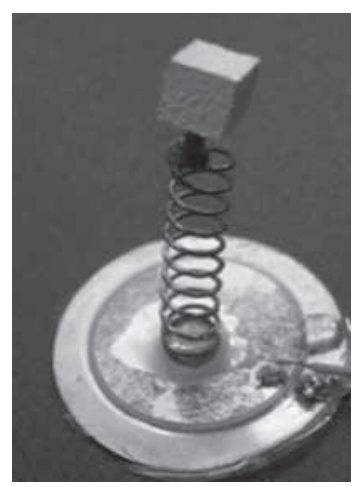

Figure 2. Earlywood specimen mounted on piezoelectric sensor.

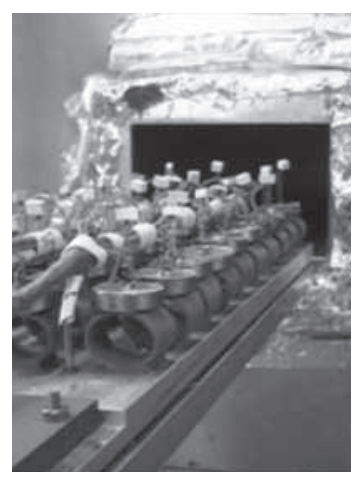

Figure 3. Specimens on the Dynamic Sorption platform 
Each sorption experiment involved cycling the humidity between two air streams, each at a constant relative humidity over a number of cycles of varying time, from 80 to 640 minutes (Figure 4). Only the data from the 640 minute cycles have been used here, since they are long enough to reach a stable equilibrium during each cycle. The air temperature was held constant at $30^{\circ} \mathrm{C}$ for all experiments.

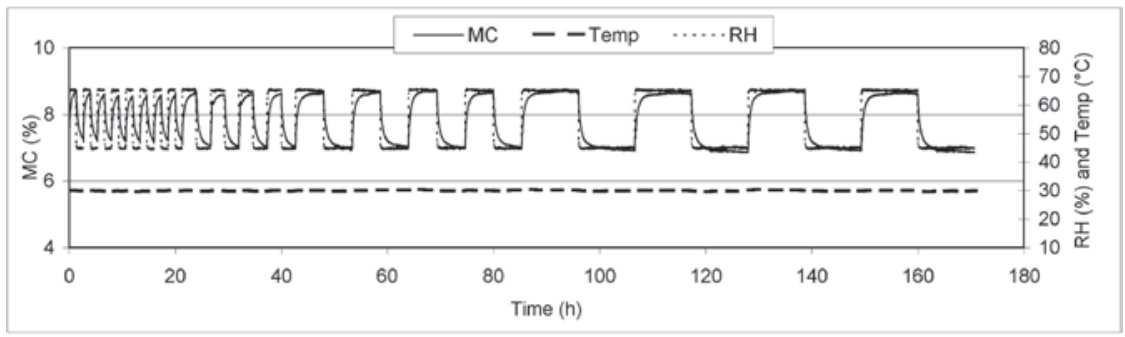

Figure 4. Moisture content changes in one specimen during an experiment, calculated from the measured mass changes. Relative humidity and temperature measurements from this experiment are also shown.

The following RH steps were used:

5-10 \%RH; 12-20 \%RH; 23-35\%RH; 34-50 \%RH; 45-65 \%RH; 55-71 \%RH; 65-78 \%RH; 75-84 $\%$ RH; 85-90 \%RH.

This gave a range of expected Equilibrium Moisture Content (EMC) values from 2-20\% Moisture Content (MC).

After the series of experiments, the dry weights of the specimens were determined by drying them at $30^{\circ} \mathrm{C}$ with compressed air (dewpoint $\sim-16^{\circ} \mathrm{C}$ ) until their weight stabilised, then drying for a further 24 hours with compressed air that had been passed through a column of silica gel desiccant. This reduced the dewpoint further to $\sim-24^{\circ} \mathrm{C}$. The lowest mass each specimen reached during the second drying stage was taken as the dry weight. This method was preferred to traditional oven drying, as the specimens are not damaged by the drying process.

\section{Analysis of Diffusion Behaviour}

Due to the small size of the specimens being used, it was possible to make the longitudinal direction of the specimens similar to the average fibre length in radiata pine $(5 \mathrm{~mm})$. From this it can be assumed that every tracheid has had one end removed, allowing vapour direct access to the internal surfaces of each cell lumen (Figure 5). Thus the majority of the diffusion is happening through the thickness of each cell wall, rather than from the outer edge of the specimen. For this reason it was decided to use an average cell wall thickness as the specimen thickness for the following analyses.

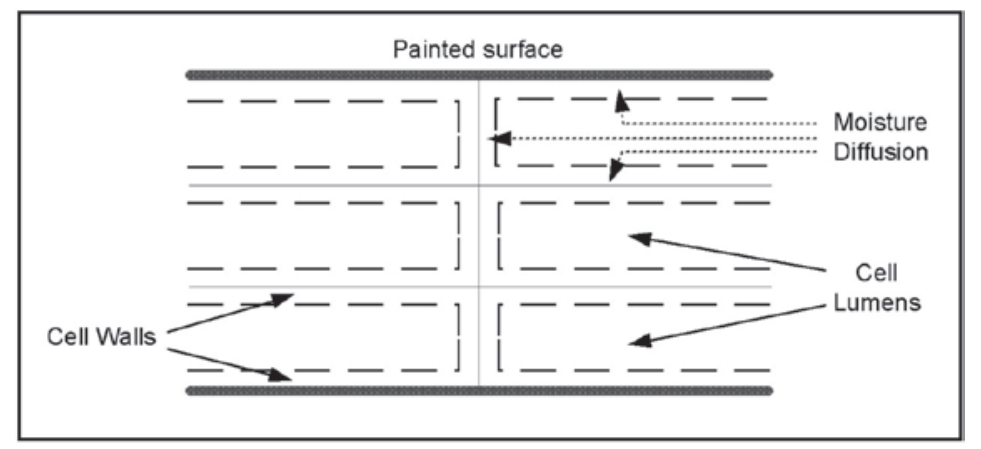

Figure 5. Simplified representation of a thin specimen with open cell ends. 
Cell wall thicknesses were estimated using Silviscan (Evans 1994, Evans et al. 1995) data from a database of typical specimens of radiata pine. Average cell wall thicknesses were calculated for earlywood and latewood, over several growth rings in the centres of the heartwood and sapwood bands of the trees. The values used were; Sapwood Earlywood $3 \mu \mathrm{m}$, Sapwood Latewood $5.25 \mu \mathrm{m}$,

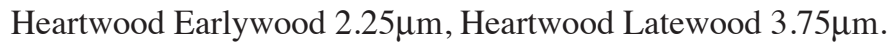

Initially the apparent diffusion coefficient was determined using an ideal Fickian response to a step change in humidity (Crank 1975, Wadsö 1994).

For absorption (wetting):

$$
E(t)=1-\frac{8}{\pi^{2}} \sum_{n=0}^{\infty} \frac{1}{(2 n+1)^{2}} \times \exp \frac{-(2 n+1)^{2} \pi^{2} D_{c}^{*} t}{4 a^{2}}
$$

Where:

$t$ is the time since the RH step (s), $\mathrm{E}(\mathrm{t})$ is the fractional mass change at time $\mathrm{t}$, a is half the cell wall thickness $(\mathrm{m}), \mathrm{D}_{\mathrm{c}}^{*}$ is the apparent diffusion coefficient $\left(\mathrm{m}^{2} / \mathrm{s}\right)$

The above equation assumes that the apparent diffusion coefficient is independent of moisture content. Although diffusion behaviour is expected to be moisture content dependent (Stamm, 1959), it has been assumed to be constant over the small moisture content range of each sorption experiment (average range of $2 \% \mathrm{MC}$ ).

Microsoft Excel and Solver were used to compare the measured data with an ideal Fickian response over four humidity cycles (Figure 6). Separate values of the apparent diffusion coefficient were used for absorption and desorption for each specimen. Solver was used to minimise the sum of squares of the difference between the two curves, by varying the values of the apparent diffusion coefficient.

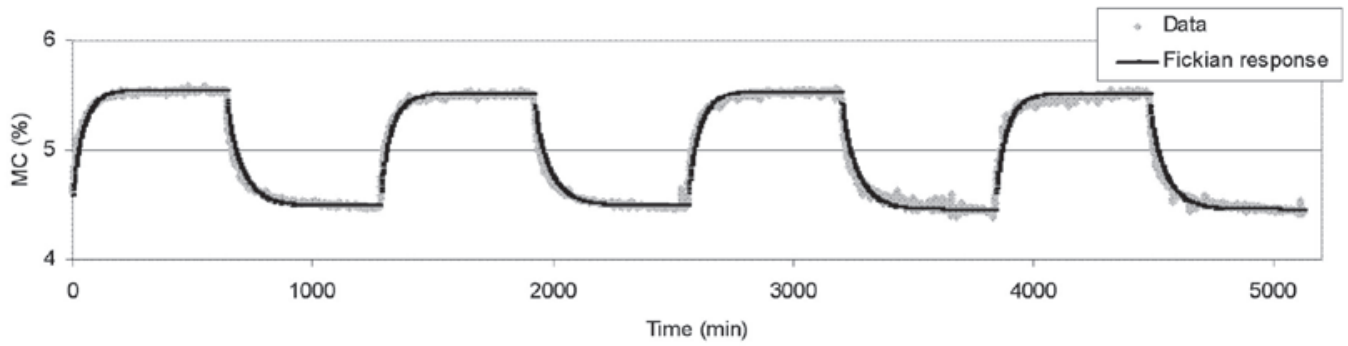

Figure 6. Calculated moisture content change over time using Equations 1 (apparent diffusion coefficient), compared to measured data.

\section{Separating internal and external resistances}

The apparent diffusion coefficient found above combines the internal resistance to diffusion (water moving within the wood) and the surface resistance (water arriving on or leaving from the wood surface). For a more complete understanding of the sorption dynamics these need to be separated. Because all cell lumens are open to the atmosphere (Figure 5), diffusion within the wood measured will primarily be within the cell walls. Thus the diffusion coefficients measured are expected to be similar to the bound-water diffusion coefficients found by Stamm (1959). 
Newman's solution to Fick's second law (Equations 2 to 5) can be used to separate the diffusion coefficient from the surface emission coefficient.

$$
\bar{E}=2 L^{2} \sum_{n=1}^{\infty} \frac{\exp \left(-\beta_{n}^{2} \tau\right)}{\beta_{n}^{2}\left(\beta_{n}^{2}+L^{2}+L\right)}
$$

$\bar{E}$ is the fractional mass change of the specimen

$\beta_{n}$ are the positive roots of

$$
\beta_{n} \tan \beta_{n}=L
$$

Where

$$
L=\frac{h_{c} a}{D}
$$

And

$$
\tau=\frac{D t}{a^{2}}
$$

$D$ is the diffusion coefficient $\left(\mathrm{m}^{2} / \mathrm{s}\right)$,

$h_{c}$ is the surface emission coefficient $(\mathrm{m} / \mathrm{s})$

$t$ is time (s)

$a$ is the specimen half thickness (m)

Previously a simplex search method has been used to vary $D$ and $h$ to fit a curve to experimental data (Cai and Avramidis 1997). Their method was adapted for use with Solver in Microsoft Excel for this work. Different values of $D$ and $h_{c}$ were calculated for absorption and desorption for each specimen. From these values an idealised sorption curve was generated, and this was compared to the measured data. Solver minimised the sum of squares of the differences between the two curves by varying the values $D$ and $h_{c}$ for absorption and desorption for each specimen. A typical result is shown in Figure 7 . For each experiment, a starting point was chosen for each wood type which gave a curve shape similar to the measured data. Most combinations of $h_{c}$ and $D$ will give a square wave shaped curve, which can't be used as a starting point for an optimisation. Often several combinations of $D$ and $h_{c}$ would give a similar shaped curve, the value closest to those found by Stamm (1959), at a similar moisture content was used as a starting value. It is unclear how the correct pair of $D$ and $h_{c}$ values was determined in previous studies (Cai and Avramidis 1997, Chen et al. 1995, Shi 2007).

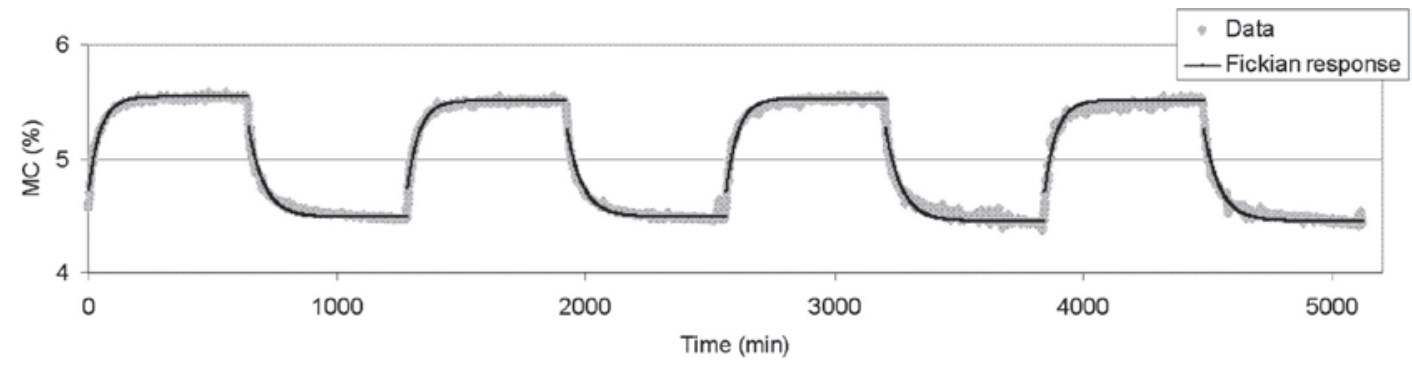

Figure 7. Calculated moisture content change over time using Equation 2 (separate diffusion, and surface emission coefficients), compared to measured data. 


\section{RESULTS AND DISCUSSION}

The quality of the signal from the piezoelectric sensors varied greatly, with some channels giving noisy signals. For each experiment, only specimens that gave a clear mass trend were used for analysis. Because of this, and the small number of specimens used in these experiments, specimens were grouped together for analysis e.g. when comparing different heat treatments, specimens from each wood type were considered together.

\section{Equilibrium Moisture Content}

The average moisture content that the specimens reached during absorption and desorption for each humidity condition, and each drying treatment are given in Figure 8.

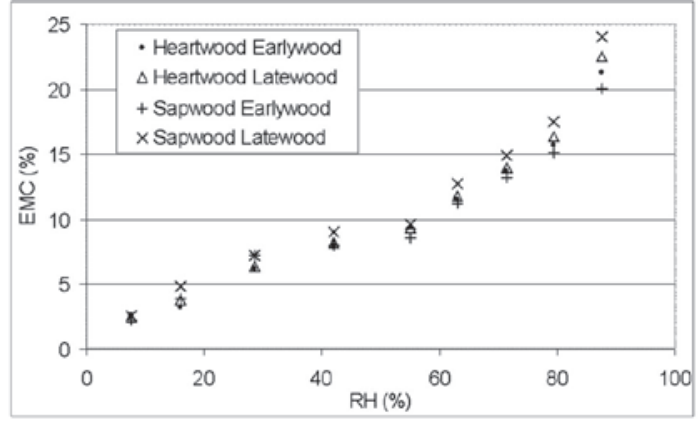

(a)

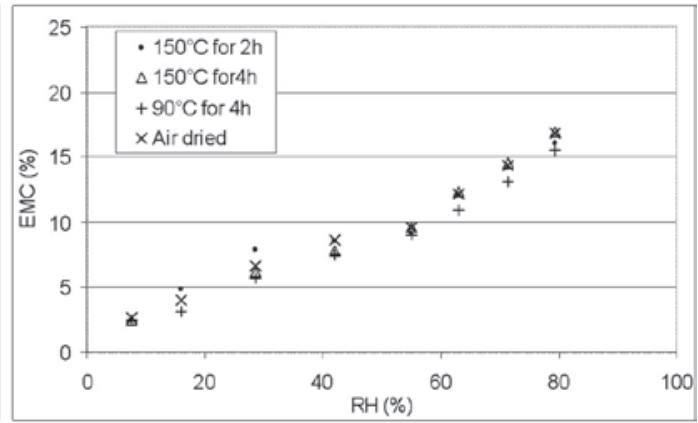

(b)

Figure 8. Average EMC for each wood type (a), and each drying treatment (b)

The different wood types (heartwood, sapwood), and position in the growth ring (earlywood, latewood) did not appear to have different equilibrium moisture contents. Moisture contents averaged over all wood types were slightly lower in absorption than in desorption, which would be expected.

Surprisingly the different heat treatments did not alter the EMC of the wood. Drying history is known to alter the sorption behaviour of the wood, also altering the equilibrium moisture content (Kininmonth and Whitehouse 1991, Kininmonth 1976, Edvardsen and Sandland 1999).

\section{Apparent diffusion coefficients}

The calculated apparent diffusion coefficients for each humidity step are given in Figure 9. The diffusion coefficients are plotted against the expected equilibrium moisture content for radiata pine for each step.

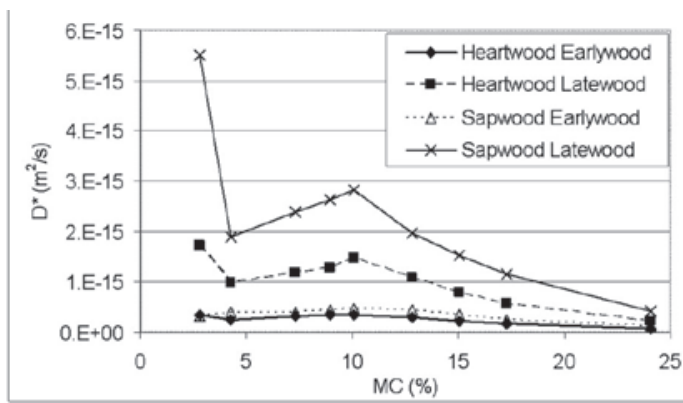

(a)

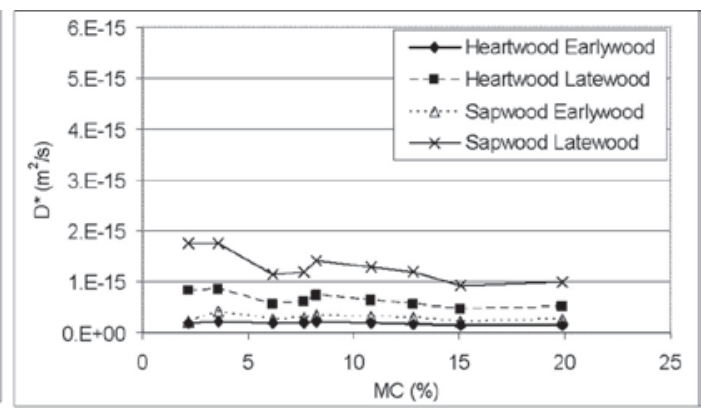

(b)

Figure 9. D* values for absorption (a), and desorption (b), averaged over all heat treatments 
Apparent diffusion coefficients for earlywood in heartwood and in sapwood were similar, whereas latewood specimens showed distinctly higher diffusion coefficients than earlywood, and showed different diffusion coefficients in heartwood and in sapwood. Apparent diffusion coefficients in latewood specimens showed a greater moisture content dependence than earlywood. For example diffusion coefficients during adsorption for sapwood earlywood varied from $3.2 \times 10^{16} \mathrm{~m} / \mathrm{s}$ at $2 \% \mathrm{MC}$ to $1.4 \times 10^{16} \mathrm{~m} / \mathrm{s}$ at $19 \% \mathrm{MC}$, whereas diffusion coefficients for sapwood latewood varied from $5.5 \times 10^{15}$ $\mathrm{m} / \mathrm{s}$ to $4.3 \times 10^{16} \mathrm{~m} / \mathrm{s}$ over the same range. Diffusion coefficients were higher at very low moisture contents, and then decreased rapidly over 5\% MC. Apparent diffusion coefficient then has another peak around $10 \% \mathrm{MC}$, and then decreases at higher moisture content. Very little change in apparent diffusion coefficient with moisture content was seen in earlywood.

Diffusion within the wood, and at the wood surface are both expected to be moisture content dependent to differing degrees, so grouping them together may give the appearance of moisture content independence.

\section{Diffusion coefficients and surface emission coefficients}

Diffusion and surface emission coefficients for each wood type and each drying condition are shown in figures 10 to 12 .

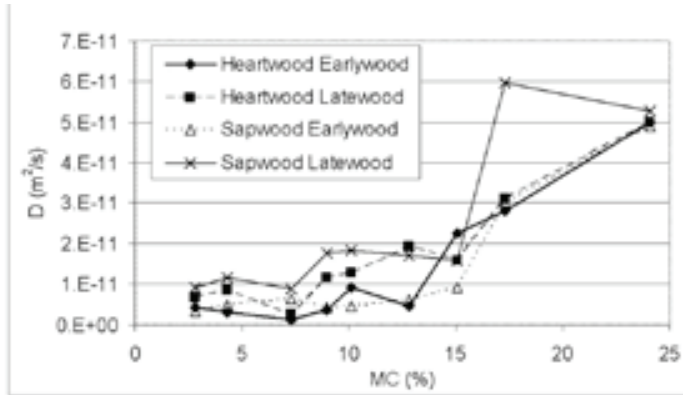

(a)

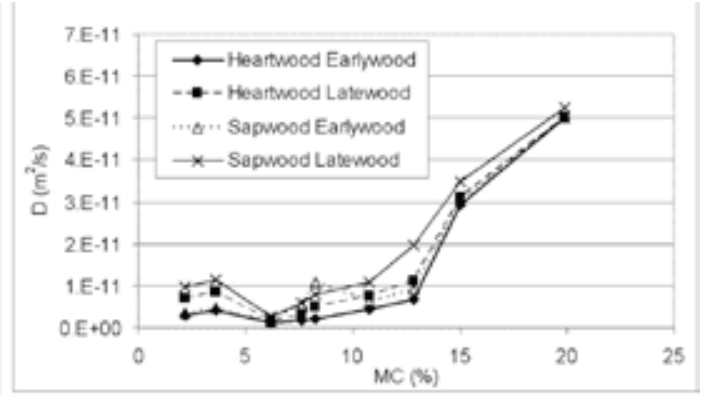

(b)

Figure 10. Diffusion coefficients for absorption (a), and desorption (b) averaged over all heat treatments

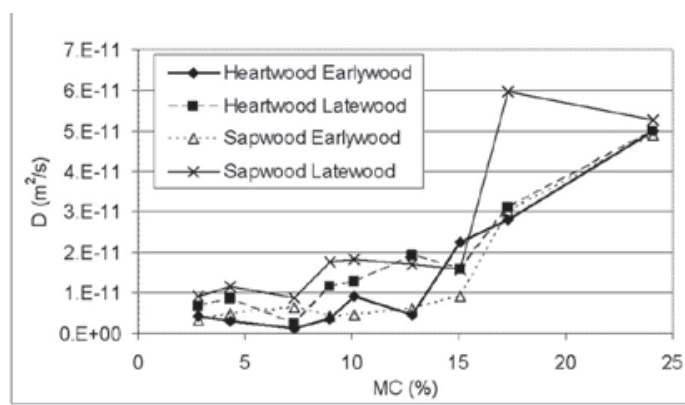

(a)

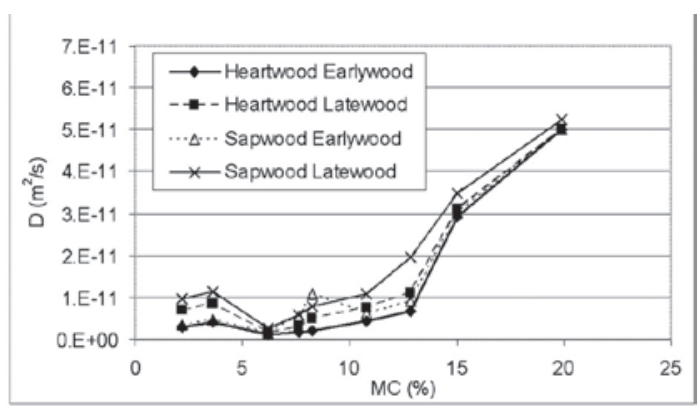

(b)

Figure 11. Surface emission coefficient for absorption (a), and desorption (b), averaged over all heat treatments 


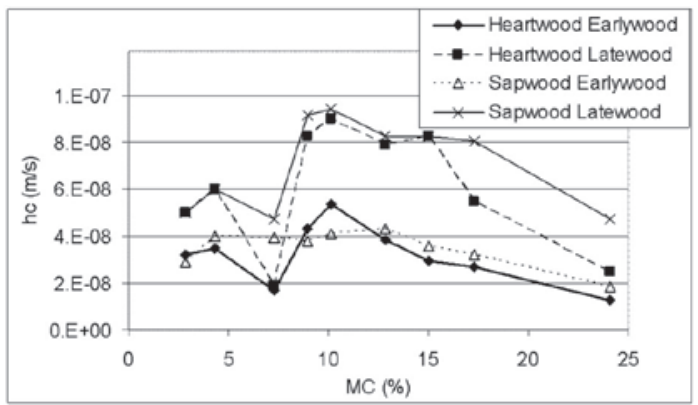

(a)

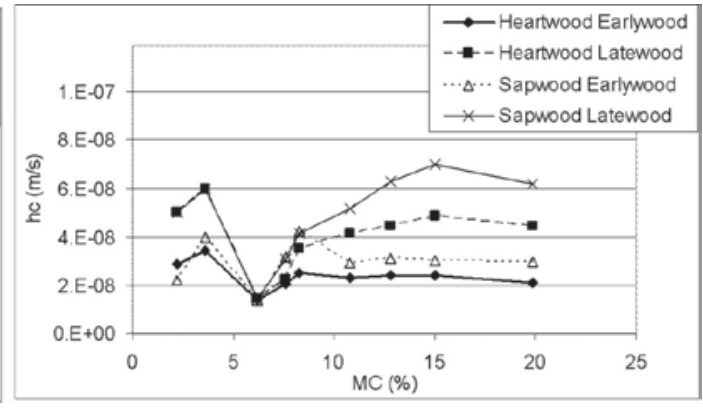

(b)

Figure 12. Diffusion coefficients (a), and surface emission coefficients (b), averaged over all wood types, and between sorption and desorption

When the apparent diffusion coefficient is separated into internal diffusion (diffusion coefficient) and surface effects (surface emission coefficient) the diffusion coefficients show a much stronger moisture content dependence compared to the apparent diffusion coefficients shown above. Diffusion coefficients for each wood type tended to increase with increasing moisture content. This generally follows the results from Stamm (1959) and Rosen (1976) who found that diffusion coefficients increase exponentially with increasing moisture content. In the current work diffusion coefficients increase with increasing moisture content, but do not follow an exponential relationship, especially at high moisture contents where diffusion coefficients are lower than would be predicted by an exponentialshaped relationship. Latewood specimens tended to have higher diffusion coefficients, but this effect was not as pronounced as for the apparent diffusion coefficients. This result is surprising, as the different wood types have different structures and cell wall thicknesses, but absorb and lose moisture at a similar rate overall. The large difference in apparent diffusion coefficients between absorption and not seen in either the diffusion coefficient, or surface emission coefficient results.

Surface emission coefficients varied much more with wood type than the diffusion coefficients, with latewood specimens having higher coefficients, and sapwood having higher coefficients than heartwood for both wood types. This result is surprising, as the surface effects were expected to be strongly linked to external conditions, such as ambient humidity, and to be similar for all wood specimens in each experiment, since they are exposed to the same humid atmosphere.

There are no clear differences in diffusion coefficients and surface emission coefficients for different heat treatments. It is known that some drying treatments affect the EMC of wood, and reduce the ability to absorb moisture (Kininmonth and Whitehouse 1991, Kinimonth 1976, Edvardsen and Sandland 1999), and thermal modification has been shown to change the sorption behaviour (Pfriem et al.2010) so it is surprising that no effect is seen here. It may be that heat treatment of previously air dried wood, as performed here, does not adequately simulate the changes that radiata pine undergoes during high temperature drying. In retrospect it is thought that the dry nature of these heat treatment conditions limited the amount of degradation that occurred. The presence of water during normal kiln drying is known to catalyze enhanced thermal degradation when compared to heat alone.

There may be several pairs of similar $h_{c}$ and $D$ values that give similar shaped curves from Newman's solution (Equation 2), and if there are several pairs of values it is unclear how to determine which the 'true' pair is. This may explain some of the scatter in the results, but it is not known whether this would explain the unexpectedly strong dependence of surface emission coefficient on wood type. In future, new experiments, such as those in and Liu (1991), which use pairs of sorption experiments between one humidity, and two others (e.g. 5-10\% RH, and 5-15\% RH) could be used to separate the internal and surface diffusion coefficients, and validate the current results. 


\section{CONCLUSIONS}

Apparent diffusion coefficients were very different for each wood type, especially for latewood. Little moisture content dependence is seen.

After removing the surface effects, the diffusion coefficients increase with increasing moisture content. The surface emission coefficients did not show a relationship with specimen moisture content. Diffusion coefficients were similar for all wood types, but surface emission coefficients were quite different for each wood type. The heat treatments used did not alter the EMC or sorption behaviour of the wood.

Further experiments, using different methods of separating the diffusion and surface emission coefficients would be useful to validate the results from these experiments.

\section{REFERENCES}

Cai, L. 2005. Determination of diffusion coefficients for sub-alpine fir. Wood Science and Technology 39(2): 153-162.

Cai, L.; Avramidis, S. 1997. A study on the separation of diffusion and surface emission coefficients in wood. Drying Technology 15: 1457-1473

Chen, Y.; Choong, E.T.; Wetzel, D.M. 1995. Evaluation of diffusion coefficient and surface emission coefficient by and optimization technique. Wood and Fiber Science 27(2): 178-182

Crank, J. 1975. The mathematics of diffusion Oxford, UK: Oxford University Press

Evans, R. 1994. Rapid measurement of the transverse dimensions of tracheids in radial wood sections from Pinus radiata. Holzforschung 48(2): 168-172

Evans, R.; Downes, G.; Menz, D.; Stringer, S. 1995. Rapid measurement of variation in tracheid transverse dimensions in a radiata pine tree. Appita Journal 48(2): 134-138

Kininmonth, J.A.1976. Effect of timber drying temperature on subsequent moisture and dimensional changes. New Zealand Journal of Forestry Science, 6(1): 101-107.

Kininmonth, J.A.; Whitehouse, L. J. 1991. Properties and uses of New Zealand radiata pine. Volume 1, wood properties. Rotorua, New Zealand: Ministry of Forestry, Forest Research Institute

Liu, J.Y. 1989. A new method for separating diffusion coefficient and surface emission coefficient. Wood and Fiber Science 21(2): 133-141

Liu, J. Y.; Simpson, W. T. 1996. Mathematical relationship between surface emission and diffusion coefficients. Drying Technology 14(3-4): 677-699.

Pfriem, A.; Zauer, M.; Wagenführ, A. 2010. Alteration of the unsteady sorption behaviour of maple (Acer pseudoplatanus L.) and spruce (Picea abies (L.) Karst.) due to thermal modification. Holzforschung, 64: 635-641

Riley, S.; Emms, G.; Sargent, R.; Schöttle, L. 2008. A method for studying dynamic sorption behaviour of small wood samples. Drying Technology 26: 1129-1134. Also in Proceedings $10^{\text {th }}$ IUFRO Wood Drying Conference

Rosen, H. 1976. Exponential Dependency of the Moisture Diffusion Coefficient on Moisture Content. Wood Science 8(3): 174-179 
Shi, S.Q. 2007. Diffusion model based on Fick's second law for moisture absorption process in wood fiber-based composites: is it suitable or not? Wood Science and Technology 41(8): 645-658

Simpson, W.T.; Liu, J.Y. 1991. Dependence of the water vapor diffusion coefficient of Aspen (Populus spec.) on moisture content. Wood Science and Technology 26(1): 9-21

Stamm, A.J. 1959. Bound-water diffusion into wood in the fiber direction. Forest Products Journal 9: $27-32$

Van der Zanden, A. J. J.; Goossens, E. L. J. 2003. The measurement of the diffusion coefficient and the sorption isotherm of water in paint films. Chemical Engineering Science 58(8): 1521-1530.

Wadsö, L. 1993. Surface mass transfer coefficients for wood. Drying Technology 11(6): 1227-1249

Wadsö, L. 1994. A test of different methods to evaluate the diffusivity from unsteady-state sorption methods. Drying Technology 12: 1863-1876 
